\title{
Características relevantes das instalações e da gestão de abrigos públicos de animais no estado do Paraná, Brasil, para o bem-estar animal
}

\author{
[Relevant characteristics of facilities and management of public animal shelters in the state \\ of paraná, Brazil, for animal welfare] \\ E.C. Arruda ${ }^{1}$, J. Noronha ${ }^{2}$, C.F.M. Molento ${ }^{3}$, R.C.M. Garcia ${ }^{3}$, S.T. Oliveira ${ }^{3}$ \\ ${ }^{1}$ Aluno de pós-graduação - Universidade Federal do Paraná - Curitiba, PR \\ ${ }^{2}$ Aluno de graduação - Universidade Federal do Paraná - Curitiba, PR \\ ${ }^{3}$ Universidade Federal do Paraná - Curitiba, PR
}

\begin{abstract}
RESUMO
Animais podem ser eventualmente recolhidos em abrigos públicos no Brasil e o ambiente de alojamento afeta diretamente sua qualidade de vida. Este trabalho estudou características relevantes das instalações físicas e da gestão dos estabelecimentos vinculados ao poder público municipal que abrigam cães, gatos e cavalos no estado do Paraná. Foram registrados 17 municípios com 20 abrigos, dos quais 18 participaram da pesquisa. Todos os municípios mantinham cães, sete $(41,2 \%)$ mantinham gatos e oito $(47,1 \%)$ mantinham cavalos. Todos os abrigos apresentavam recintos coletivos; dois $(11,8 \%)$ de cães e cinco $(71,5 \%)$ de gatos mantinham um animal por recinto; quatro $(22,2 \%)$ mantinham recintos sem visualização além do próprio recinto; $11(64,7 \%)$ realizavam limpeza adequadamente; cinco $(29,4 \%)$ abrigos de cães e um $(14,3 \%)$ de gatos não tinham área para quarentena ou isolamento sanitário; camas estavam disponíveis em $15(88,2 \%)$, cinco $(71,4 \%)$ e um $(12,5 \%)$ dos recintos de cães, gatos e cavalos, respectivamente. Os abrigos de animais no Paraná devem banir recintos de isolamento social, incluir uma cama por animal e socializar os animais. Adicionalmente, há oportunidade de aumentar o grau de bem-estar animal por meio de melhorias no manejo dos animais e no manejo sanitário, as quais não dependem de reformas nas instalações.
\end{abstract}

Palavras-chave: cães, gatos, cavalos, estabelecimentos municipais, abrigos de animais, bem-estar animal, legislação

\begin{abstract}
Animals may be eventually collected by public shelters in Brazil and the shelter's environment directly affects their quality of life. This work studied relevant characteristics of the physical facilities and the management of establishments liked to the municipal public power that shelter dogs, cats and horses in the state of Paraná. It was registered 17 municipalities with 20 shelters, of which 18 participated in the research. All the municipalities maintained dogs, seven (41.2\%) maintained cats and eight (47.1\%) kept horses. All the shelters had social housing; two (11.8\%) of dogs and five (71.5\%) of cats housing one animal per pen; four (22,2\%) there were pens that didn't have visualization for outside; 11 (64.7\%) had cleaning correctly; five (29.4\%) shelters that sheltered dogs and one (14.3\%) that sheltered cats didn't have area for quarantine and isolation restroom; beds were available in 15 (88.2\%), five (71.4\%) and one (12.5\%) of the pens of dogs, cats and horses, respectively. Animal shelters in Paraná should ban pens isolation, include one bedding per animal and socialize the animals. In addition, there is an opportunity to increase the animal welfare through improvements in animal management and sanitary management, which do not depend on the housing improvements.
\end{abstract}

Keywords: dogs, cats, horses, municipal establishments, animal shelters, animal welfare, legislation

Recebido em 4 de agosto de 2017

Aceito em 17 de abril de 2018

E-mail: ecarruda.ufpr@gmail.com 


\section{INTRODUÇÃO}

O descontrole da população de cães e gatos nas ruas é percebido pela sociedade como um problema, tanto pelo risco de zoonoses quanto pelo reconhecimento, mais recente, do sofrimento animal. A ineficiência do controle populacional de animais errantes por meio do recolhimento e extermínio ocorre por vários motivos, tais como a ocupação do ambiente por novos animais, rápida reprodução e falta de guarda responsável quanto à sanidade, castração dos animais e restrição do livre acesso às ruas (Molento, 2014). O Paraná, que anteriormente recolhia cães e gatos de rua para extermínio, passou a ter outras abordagens para o controle animal. Em 2012, foi aprovada a Lei Estadual $n^{\circ}$ $17.422 / 12$, que veda o extermínio de cães e gatos para fins de controle da população, assim como em outros estados federativos e municípios que elaboraram leis protetivas aos animais ou que foram impedidos pelo Ministério Público de eliminar animais sadios para o controle populacional. As instalações construídas para o controle da raiva, que mantinham animais de três a 10 dias até a sua eliminação, hoje são utilizadas para a manutenção mais longa, por vezes permanente, de animais recolhidos.

Os abrigos tornam-se instalações que mantêm uma quantidade considerável de animais, vindos comumente de situações de risco ou abandono. Segundo Miller e Zawistowski (2013), nesses estabelecimentos, os animais recolhidos devem ser reabilitados, ressocializados e reintroduzidos na sociedade por meio da adoção, ou seja, são locais de passagem; devem ser referência em cuidados veterinários, bem-estar animal e na promoção de programas educativos quanto à guarda responsável, trabalhando para a prevenção do abandono. Os abrigos podem ser de responsabilidade governamental, privada, de organização não governamental (ONG) ou mista. No Paraná, os abrigos de responsabilidade governamental incluem Canis Municipais (CM), Centros de Controle de Zoonoses (CCZ), Unidades de Vigilância em Zoonoses (UVZ) (Brasil..., 2016), Centros de Triagem Animal (CTA) e de Referência para Animais em Risco (Crar) (Animais..., 2016).

Com base na nova realidade, os abrigos têm procurado adequar suas instalações para alojamentos dos cães, gatos e cavalos, capacitar seus funcionários, investir em educação sobre guarda responsável para a população do município e incentivar a adoção dos animais. A esterilização desses animais também é fundamental para um programa efetivo de manejo humanitário, fazendo parte de políticas públicas de alguns municípios paranaenses e realizada por alguns abrigos municipais, por clínicas e universidades de veterinária parceiras ou por ONGs. Sugere-se ainda estabelecer o número de animais a serem alojados no abrigo e suas categorias; implantar, monitorar e avaliar a eficiência dos programas; elaborar, divulgar e aplicar leis relacionadas à proteção animal; registrar e identificar os animais; ofertar tratamentos veterinários preventivos para proteger a saúde e o bem-estar dos animais e para diminuir o risco zoonótico. Segundo a ICAM (Componentes..., 2014), a eutanásia deve ser empregada para animais em sofrimento por doenças ou ferimentos incuráveis e por problemas de comportamento que os impeçam de ser realocados, ou para aqueles que não estejam se adaptando às condições do abrigo para que se mantenha um nível mínimo de bem-estar.

Existe reconhecimento científico contemporâneo sobre a senciência animal (Declaração de Cambrigde, 2012), e seu grau de bem-estar é definido como o estado mental e físico do animal com base em suas tentativas de se adaptar ao ambiente em que se encontra (Broom, 1986). Portanto, conhecer o ambiente de manutenção dos animais de abrigos e a sua gestão é fundamental para o diagnóstico e a implantação de melhorias segundo as recomendações existentes para a medicina veterinária de abrigos (Miller e Zawistowski, 2014).

O objetivo desta pesquisa foi traçar o perfil das instalações, do manejo dos animais e do manejo sanitário dos estabelecimentos de responsabilidade do poder público municipal que recolhem cães, gatos e cavalos no estado do Paraná, com o intuito de identificar os pontos relevantes para a tomada de decisões, a fim de melhorar o grau de bem-estar dos animais.

\section{MATERIAL E MÉTODOS}

Foram quantificados e avaliados os estabelecimentos municipais vinculados ao poder público que alojam cães, gatos e cavalos no estado do Paraná, por meio de informações 
obtidas junto ao CRMV-PR. Em seguida, foi elaborado um questionário com 18 perguntas relacionadas às instalações físicas dos abrigos $\mathrm{e}$ ao manejo sanitário e dos animais. $\mathrm{O}$ questionário foi semiaberto, com questões de múltipla escolha, de resposta única ou múltipla, e com a opção "outro", na qual os entrevistados puderam acrescentar itens novos. A aplicação do questionário foi realizada por meio de entrevista pelo telefone. O questionário incluiu perguntas sobre motivos que levavam o estabelecimento a recolher animais; espécies mantidas; número atual de animais; tipos de recintos, se coletivos, individuais ou gaiolas; tamanho dos recintos; tempo médio de permanência dos animais no abrigo; características dos recintos, como paredes, grades, quintal; material do piso; recursos dentro dos recintos, como cama, caixa de areia, enriquecimento ambiental; possibilidades visuais para o animal dentro do recinto, se apenas paredes, pessoas no corredor, ambiente externo; soltura em área externa cercada durante o dia; modo de oferta de alimento; separação entre animais sadios e doentes com sinais clínicos sugestivos de doenças infectocontagiosas, tais como secreção de mucosa ocular e nasal, tosse, espirro e diarreia; procedimentos de limpeza e desinfecção, em que foi considerado adequado varrer a instalação, usar a solução de detergente, esfregar, enxaguar, deixar secar e, então, desinfetar por método físico ou químico; realização ou não de esterilização dos cães e gatos; destino dos animais recolhidos; melhorias para o abrigo consideradas relevantes pelo respondente; e, finalmente, existência de lei municipal de proteção animal.

A entrevista foi por contato telefônico, no período de outubro de 2016 a janeiro de 2017. As perguntas foram direcionadas preferencialmente ao médico veterinário, ao gestor ou ao profissional com nível de escolaridade superior responsável pelos programas desenvolvidos pelo estabelecimento. Todas as ligações foram realizadas pela mesma pessoa. Os dados foram avaliados por meio de análise estatística descritiva. O projeto foi aprovado pelo Comitê de Ética em Pesquisa com Seres Humanos Plataforma Brasil, número 1907748.

\section{RESULTADOS}

Dos 399 municípios do estado do Paraná (População no Estado..., 2018), 17 mantinham pelo menos um estabelecimento municipal vinculado ao poder público, que recolhia $\mathrm{e}$ alojava cães, gatos ou cavalos. Nos 17 municípios, existia um total de 20 abrigos de animais, pois três municípios mantinham abrigo para cavalos separado do abrigo para cães e gatos. Desses três municípios, apenas um participou da pesquisa; dessa forma, o questionário foi respondido por profissionais de 18 abrigos, distribuídos em 17 municípios.

Dos 18 abrigos, $10 \quad(55,6 \%)$ eram de responsabilidade da Secretaria Municipal da Saúde, seis $(33,3 \%)$ da Secretaria Municipal do Meio Ambiente e dois $(11,1 \%)$ de ambas as Secretarias; oito $(44,5 \%)$ eram Canis Municipais, quatro (22\%) Centros de Controle de Zoonoses ou Unidades de Vigilância em Zoonoses, três $(16,5 \%)$ Centros de Triagem Animal, um (5,5\%) Centro de Referência para Animal em Risco e dois $(11,5 \%)$ compartilhavam as mesmas instalações, destinando alguns recintos para os animais recolhidos pelo CCZ/UVZ e outros recintos para os animais recolhidos pelo CTA/Crar (Tab. 1).

O recolhimento seletivo, considerado como atendimento às solicitações da população para remoção de animais soltos, sem supervisão, considerados como de risco à saúde e segurança da população (São Paulo, 2006; Curso..., 2017), era realizado por todos os abrigos. Foram citados 14 motivos para o recolhimento de animais, com mais de uma resposta para cada estabelecimento, tendo 70,6\% dos respondentes apontado o sofrimento dos animais em via pública, 64,7\% a mordedura em pessoas, $47,1 \%$ o abandono de animais próximo ao abrigo, $41,9 \%$ a denúncia de maus-tratos contra os animais e $16,7 \%$ a presença de cães de grande porte ou de raças consideradas perigosas soltos em via pública. Dos 17 estabelecimentos que mantinham cães, dois $(11,8 \%)$ capturavam, castravam e devolviam os cães nas ruas. Um dos municípios estava proibido judicialmente de recolher novos animais no abrigo. Todos os 17 municípios participantes mantinham animais para adoção. 
Tabela 1. Número (percentual) de abrigos vinculados ao poder público no Paraná, de acordo com o número de cães, gatos e cavalos alojados em cada tipo de estabelecimento, entre outubro de 2016 e janeiro de 2017

\begin{tabular}{|c|c|c|c|c|c|c|c|c|c|c|c|}
\hline \multirow[t]{2}{*}{$\begin{array}{c}\text { Espéci } \\
\text { e }\end{array}$} & \multirow[t]{2}{*}{$\begin{array}{l}\text { Quantidade } \\
\text { de animais }\end{array}$} & \multicolumn{2}{|c|}{$\mathrm{CM}$} & \multicolumn{2}{|c|}{ CCZ/ UVZ } & \multicolumn{2}{|c|}{ CTA/ Crar } & \multicolumn{2}{|c|}{$\begin{array}{l}\text { CCZ/UVZ } \\
+ \text { CTA/Crar }\end{array}$} & \multicolumn{2}{|c|}{ Total } \\
\hline & & $\mathrm{n}$ & $(\%)$ & $\mathrm{N}$ & $(\%)$ & $\mathrm{n}$ & $(\%)$ & $\mathrm{N}$ & $(\%)$ & $\mathrm{n}$ & $\%$ \\
\hline \multirow{5}{*}{ Cães } & Nenhum & - & & - & & - & & - & & 0 & - \\
\hline & 1 a 30 & 1 & (12) & 3 & $(75)$ & 1 & $(33,3)$ & 2 & $(100)$ & 7 & 41 \\
\hline & 31 a 100 & 5 & $(62,5)$ & 1 & (25) & 2 & $(66,7)$ & - & & 8 & 47 \\
\hline & 101 a 150 & - & & - & & - & & - & & 0 & - \\
\hline & $>150$ & 2 & (25) & - & & - & & - & & 2 & 12 \\
\hline \multirow{4}{*}{ Gatos } & Nenhum & - & & 2 & $(66,7)$ & - & & - & & 2 & 28,6 \\
\hline & 1 a 10 & - & & 1 & $(33,3)$ & - & & 1 & $(50)$ & 2 & 28,6 \\
\hline & 11 a 20 & - & & - & & 1 & $(100)$ & 1 & $(50)$ & 2 & 28,6 \\
\hline & 21 a 50 & - & & - & & - & & - & & 0 & - \\
\hline \multirow{5}{*}{$\begin{array}{l}\text { Caval } \\
\text { os }\end{array}$} & $>50$ & 1 & (100) & - & & - & & - & & 1 & 14,2 \\
\hline & Nenhum & 1 & (100) & 1 & (50) & 1 & $(33,3)$ & 2 & (100) & 5 & 62,5 \\
\hline & apenas 1 & - & & 1 & (50) & - & & - & & 1 & 12,5 \\
\hline & 2 a 5 & - & & - & & 1 & $(33,3)$ & - & & 1 & 12,5 \\
\hline & $>5$ & - & & - & & 1 & $(33,3)$ & - & & 1 & 12,5 \\
\hline
\end{tabular}

*CM = Canil Municipal; CCZ = Centros de Controle de Zoonoses, UVZ = Unidade de Vigilância em Zoonoses; CTA $=$ Centro de Triagem Animal; Crar = Centro de Referência para Animais em Risco.

Todos os municípios mantinham abrigos que alojavam cães; sete recolhiam exclusivamente cães, cinco apresentavam estrutura física para abrigar cães, gatos e cavalos, três para abrigar cães e cavalos, e dois para abrigar cães e gatos (Tab. 1). Dos oito estabelecimentos que apresentavam estrutura física para abrigar cavalos, seis relataram problemas com degradação proposital da estrutura física, seguida de furto dos cavalos durante a noite, período em que os animais não eram vigiados; os episódios repetidos de furto levaram à cessação temporária do recolhimento de cavalos nesses estabelecimentos, sendo a adoção imediata a estratégia utilizada. Os cavalos recolhidos eram de carroceiros, vítimas de maus-tratos ou estavam soltos em via pública. Os estabelecimentos que recolhiam animais acreditavam que os furtos dos cavalos tinham envolvimento com os donos dos animais, os quais se negavam a pagar as diárias do abrigo e as multas referentes à infração que levou ao recolhimento. Visando acabar com os maustratos aos cavalos de carroceiros, alguns municípios no Paraná possuem respaldo legal municipal para proibir ou regulamentar o uso de veículos de tração animal, tais como Curitiba (Lei 14741/15), Foz do Iguaçu (Lei 3512/08), Ponta Grossa (Lei 9010/07) Paranaguá (Lei 382/05), Pinhais (Lei 1374/12), São José dos
Pinhais (Lei 1330/09) e Apucarana (Lei 218/12). O objetivo nesses municípios não foi alcançado plenamente devido a outros fatores socioeconômicos e políticos e à fiscalização insuficiente. Dos sete abrigos que mantinham gatos, todos relataram dificuldade na captura dessa espécie, exceto nas solicitações de recolhimento em que os gatos eram encontrados severamente debilitados, sendo a eutanásia imediata o recurso utilizado; os quatro $\mathrm{CCZ}$ recolhiam apenas gatos com alto potencial de transmitir zoonoses, dois relataram abandono comum de indivíduos dessa espécie próximo ao estabelecimento, e um abrigo relatou denúncia de maus-tratos como sendo a principal causa para acolhimento de gatos. A distribuição das espécies e o número de animais por tipo de estabelecimento estão descritos na Tab. 1 .

Quanto à forma da manutenção dos animais, todos os abrigos tinham mais de um tipo de recinto e de piso para uma mesma espécie animal em um mesmo abrigo. Para os abrigos que mantinham cães, todos possuíam recintos coletivos, nove $(52,9 \%)$ mantinham também recintos individuais, quatro $(23,5 \%)$ deixavam os cães soltos em áreas livres e quatro $(23,5 \%)$ mantinham cães presos em correntes. Quanto ao piso dos recintos, oito $(47,1 \%)$ relataram piso de cimento queimado, sete $(41,7 \%)$ de cimento, 
quatro $(23,5 \%)$ de grama, dois $(11,8 \%)$ de lajota, dois $(11,8 \%)$ de pedregulhos, um $(5,9 \%)$ de cepilho e um $(5,9 \%)$ de cimentina. Para os abrigos que mantinham gatos, quatro $(57,1 \%)$ possuíam gaiolas; três $(42,9 \%)$, gatis coletivos de alvenaria; dois $(28,6 \%)$, área externa não cercada; e um $(14,3 \%)$, gatil individual de alvenaria. Quanto ao piso dos recintos dos gatos, três $(43,84 \%)$ eram de cimento queimado, um $(14,3 \%)$ de lajota e um $(14,3 \%)$ de areia. Para os abrigos de cavalos, todos mantinham os animais soltos em área externa cercada. $\mathrm{O}$ piso dos cavalos era de cimento queimado (dois, 33,3\%), de cimento (dois, 33,3\%), de grama (dois, $33,3 \%$ ), de terra (um, $16,7 \%$ ) e de pedregulho (um, 16,7\%).

Quando os participantes foram questionados sobre o tamanho dos recintos, $13(72,2 \%)$ não souberam responder com exatidão e também tiveram dificuldade de estimar um valor aproximado. Essa mesma dificuldade foi apresentada quando foi questionado o tempo de permanência dos animais naquele estabelecimento.

Em $14(82,3 \%)$ estabelecimentos, os animais podiam ver o ambiente externo, em nove $(52,9 \%)$ visualizar pessoas nos corredores, em oito $(47,1 \%)$ visualizar os animais que estavam nos recintos da frente, em cinco $(29,4 \%)$ visualizar os animais na lateral e em frente, em três $(17,6 \%)$ conseguiam ver apenas animais que estavam alojados no mesmo recinto e em quatro $(23,5 \%)$ os animais visualizavam apenas as paredes. Em todos os abrigos, existia mais de um tipo de recinto, dessa forma a visualização de um animal podia ser diferente de outros que estavam em outro tipo de recinto no mesmo abrigo.

Em relação aos recursos encontrados no interior dos recintos dos animais, dos 17 abrigos que mantinham cães, $15(88,2 \%)$ introduziram algum material para isolar o piso para descanso (cama), seis $(35,3 \%)$ mantinham esconderijo, e quatro $(23,5 \%)$ enriquecimento ambiental, como bolinha e garrafa PET. Dos sete abrigos de gatos, seis $(85,8 \%)$ mantinham caixa de areia, cinco $(71,5 \%)$ cama, um $(14,3 \%)$ esconderijo, quatro $(57,2 \%)$ brinquedos, e um $(14,3 \%)$ arranhadores para enriquecimento ambiental. Dos seis municípios que abrigavam cavalos, apenas um $(16,7 \%)$ mantinha material de isolamento no piso para descanso dos cavalos.
Quatro $(23,5 \%)$ respondentes afirmaram levar os animais à área externa com frequência diária, oito $(47,1 \%)$ semanal, quatro $(23,5 \%)$ de maneira esporádica, um $(5,9 \%)$ levava apenas alguns cães, e dois $(11,8 \%)$ nunca tiravam os cães dos recintos. Em relação aos gatos, dois estabelecimentos $(28,6 \%)$ permitiam livre acesso ao ambiente externo não cercado, um $(14,3 \%)$ mantinha gatil com solário, e os cinco restantes $(71,5 \%)$ mantinham os gatos sempre fechados em área interna. Todos os municípios mantinham os cavalos soltos em área externa cercada.

Todos os abrigos ofereciam ração seca para cães e gatos; equinos ficavam a pasto e recebiam ração e suplementação (melaço, verdura ou feno). Cinco $(29,4 \%)$ e dois $(28,6 \%)$ abrigos ofertavam ração uma vez ao dia para cães e gatos, respectivamente; oito $(47,1 \%)$ e cinco $(71,4 \%)$ abrigos, duas vezes ao dia para cães e para gatos, respectivamente; um abrigo $(5,9 \%)$ oferecia ração três vezes ao dia para os cães; e três $(17,6 \%)$ deixavam ração ad libitum para os cães.

Quanto ao isolamento adequado de animais com sinais clínicos sugestivos de doença infecciosa, dos 17 abrigos que mantinham cães, sete $(41,2 \%)$ tinham instalações específicas para separar animais doentes dos sadios, e cinco $(29,4 \%)$ conseguiam improvisar locais para separá-los. Cinco $(29,4 \%)$ mantinham animais doentes e sadios juntos; para quatro $(80 \%)$ destes, os respondentes relataram impossibilidade de separação de sadios e doentes relacionada à instalação física, e, para um (20\%) abrigo, o respondente relatou haver pouco, senão nenhum, interesse do gestor e do profissional responsável pelos animais do abrigo nesta questão. Quanto aos gatos, seis $(85,7 \%)$ abrigos tinham instalações específicas para isolamento, e em um $(14,3 \%)$ os doentes e sadios permaneciam juntos, por impossibilidade de instalações. Em relação aos cavalos, o isolamento era possível em todos os abrigos, e quatro (50\%) improvisavam um local para separá-los. Em relação à eutanásia, os CCZ/UVZ (22\% dos estabelecimentos) mostraram-se confiantes em diagnosticar a necessidade da eutanásia dos animais com risco à saúde pública e agressivos. Nos demais estabelecimentos, os responsáveis tinham dificuldade em realizar esse diagnóstico, não sendo a eutanásia realizada nesses casos. 
Em relação aos procedimentos de limpeza e desinfecção dos recintos dos abrigos, $11(61,1 \%)$ respondentes citaram o manejo correto, porém em sete $(38,9 \%)$ abrigos os respondentes relataram procedimentos inadequados, caracterizando o manejo incorreto. Foi considerado manejo correto varrer a instalação, usar solução de detergente, esfregar o chão, enxaguar, deixar secar e, então, realizar a desinfecção por método físico ou químico. Quando não era realizado qualquer um desses procedimentos, o manejo foi considerado incorreto.

Dos 17 estabelecimentos que mantinham cães e gatos, $12(70,6 \%)$ castravam os animais. Desses 12 estabelecimentos, oito $(66,8 \%)$ realizavam as castrações cirúrgicas em clínicas conveniadas, um $(8,3 \%)$ em Unidade Móvel de Esterilização e Educação em Saúde (UMEES), um $(8,3 \%)$ por meio de parceria com $\mathrm{ONG}$, um $(8,3 \%)$ realizava o procedimento cirúrgico no próprio abrigo, e um $(8,3 \%)$ realizava mutirões de castração química de cães machos do município. Dois $(16,6 \%)$ dos estabelecimentos realizavam a captura, castração e devolução dos animais aos locais de origem após a recuperação cirúrgica, caso estes não fossem adotados nesse período. Todos os 17 municípios participantes mantinham animais para adoção, nove desses $(52,9 \%)$ promoviam eventos de adoção de cães e gatos fora do abrigo e, em oito $(47,1 \%)$, as adoções ocorriam apenas presencialmente nos abrigos. Dentre as melhorias necessárias que os respondentes consideraram mais relevantes, estavam estrutura física $(64,7 \%)$, treinamento e capacitação dos funcionários (29,4\%), introdução de enriquecimento ambiental para os animais $(23,5 \%)$ e inserção de mais funcionários nesses locais (23,5\%). Quanto à existência de lei municipal referente à proteção animal, 10 $(55,6 \%)$ responderam haver respaldo legal municipal. Em seguida, ao consultar as leis municiais dos 17 municípios, $14 \quad(82,3 \%)$ dispunham de leis municipais protetivas aos animais. Dessa forma, quatro $(22,2 \%)$ respondentes não tinham conhecimento das leis do seu município.

\section{DISCUSSÃO}

De acordo com os resultados obtidos, no estado do Paraná, 4,3\% dos 399 municípios mantinham algum tipo de estabelecimento vinculado à prefeitura para acolher animais em risco. Não se tem registro de quantos locais eram anteriormente destinados à antiga prática de extermínio animal; no entanto, sabe-se hoje que nenhum deles utiliza essa prática para controle populacional, e o recolhimento ocorre por outros motivos, como animais em sofrimento em vias públicas ou mordedura em pessoas. Em uma pesquisa realizada em 2013 no Rio Grande do Sul, um estado com 497 municípios, nos 41 CCZs ou Canis municipais cadastrados no Conselho Regional de Medicina Veterinária, foram constatadas condições precárias para o exercício da medicina veterinária, carência de estrutura física adequada, assim como ausência de garantia de bem-estar dos animais alojados (Rx dos CCZs..., 2014). Dos 18 estabelecimentos avaliados no Paraná, quatro eram CCZ ou UVZ, com finalidade de saúde pública, e, dessa forma, recolhiam animais com potencial de transmissão de zoonoses e risco à saúde pública, conforme Ministério da Saúde instituiu na Portaria $n^{\circ}$ $1.138 / 2014$. Os animais previamente recolhidos e posteriormente diagnosticados como saudáveis permaneciam à disposição para adoção. Assim, o destino final dos animais recolhidos nesses estabelecimentos mudou. Os locais onde o extermínio era praticado para controle de zoonoses e populacional de cães e gatos passaram a ser locais para vigilância de zoonoses, com animais mantidos temporariamente, como Miller e Zawistowski (2013) sugerem que sejam os abrigos locais de passagem, ou os permanentes para os animais não adotados, com a intenção de proteção, cuidado e tratamento, como regulamentado por alguns municípios. Além disso, uma das estratégias para o controle populacional deixou de ser o extermínio e passou a ser a esterilização de cães e gatos, não como responsabilidade dos abrigos, mas como programa municipal em mais de $70 \%$ dos municípios participantes.

As ações de controle populacional e as condições de abrigos oferecidas aos cães e gatos de rua representam uma crescente preocupação dos diferentes municípios brasileiros. Apesar disso, um estudo mostrou que, em sete Canis Municipais e em um CCZ de diferentes municípios de Minas Gerais, fiscalizados por denúncias ao CRMV-MG, as normas técnicas e as legislações referentes às estruturas físicas de abrigos e ações de programas de manejo populacional de cães e gatos não estavam sendo 
consultadas e seguidas (Luns e Luns, 2017). Uma vez que o governo federal anunciou a possibilidade de liberação de 24 milhões de reais para 198 propostas vinculadas à saúde para financiar castramóveis no Paraná (Ministério..., 2018), é fundamental que os gestores e os veterinários do Paraná, assim como no restante do Brasil, estejam atualizados e cumpram as orientações técnicas e legislações para evitar ações equivocadas por falta de embasamento necessário para garantir bem-estar aos animais, higiene sanitária e saúde pública.

O termo "saúde única" é a união indissociável entre a saúde animal, humana e ambiental, governada por grandes interesses e recursos; "bem-estar único" considera simultaneamente o bem-estar dos animais e do ser humano em uma situação de sustentabilidade ambiental (Você..., 2017; Pinillos et al., 2016). Dessa forma, avanços em saúde única e bem-estar animal e humano podem ser melhorados por meio de parcerias, colaborações e programas de pesquisa, vigilância e controle, mediante cooperação entre os serviços de saúde pública e de saúde animal (Dhama et al., 2017). A saúde única e o bemestar único são mais facilmente associados quando as Secretarias Municipais de Saúde (SMS) e do Meio Ambiente (SMMA) trabalham em conjunto. Isso parece estar sendo iniciado no estado do Paraná em dois $(11,1 \%)$ abrigos de gestão conjunta entre SMS e SMMA.

A maioria dos CCZ/UVZ, Canis Municipais e CTA/Crar mantinha uma quantidade máxima de 10, 63 e 20 cães, respectivamente. A maioria dos abrigos mantinha um gato e até dois cavalos. Tais dados podem aparentar que os abrigos do Paraná mantinham um pequeno número de animais por abrigo. No entanto, a densidade de lotação e o tempo de permanência são os fatores relevantes quando se considera bem-estar dos animais em condição de abrigo e devem ser levados em consideração. Segundo Barnard et al. (2014), o tempo de permanência deve ser o menor possível e a mensuração da densidade de lotação deve ser feita de acordo com o peso do animal e a área disponível. A recomendação é de $4 \mathrm{~m}^{2}$ de área para um cão de até $20 \mathrm{~kg}$ de peso corporal e $2 \mathrm{~m}^{2}$ adicionais para cada cão de até $20 \mathrm{~kg}$ introduzido a mais no recinto; para cães acima de $20 \mathrm{~kg}$, a recomendação é de $8 \mathrm{~m}^{2}$ por animal e $4 \mathrm{~m}^{2}$ adicionais para cada cão acima de $20 \mathrm{~kg}$ introduzido no recinto (Barnard et al.,
2014). Em relação aos gatos, um estudo mostrou que o tamanho do recinto não é o mais importante. Os gatos mantidos em gaiolas individuais e estéreis (apenas com comedouro e bebedouro), com manuseio apenas para higiene e alimentação, apresentaram mais comportamento de medo e estresse e tiveram $30 \%$ menos adotabilidade, comparados com gatos mantidos em gaiolas individuais ou gatis coletivos, ambos com enriquecimento ambiental e um manuseio mais frequente pelos funcionários (Gourkow e Fraser, 2006).

Para cavalos, o tamanho recomendado também varia de acordo com o peso do animal, de $5,5 \mathrm{~m}^{2}$ a $12 \mathrm{~m}^{2}$ (Minero et al, 2015). As dificuldades de resposta dos participantes sobre o tamanho dos recintos e sobre o tempo de permanência dos animais no estabelecimento demonstram que a gestão dos respectivos abrigos não apresentava condições de perceber problemas relativos às questões de espaço disponíveis aos animais e tempo de permanência nos recintos, fato também possivelmente associado à atribuição de baixa importância a tais questões. No entanto, o tempo de permanência dos cães em um abrigo e as condições de manutenção desses animais comprometem diretamente sua saúde mental, seu grau de bem-estar e podem dificultar sua realocação permanente em um novo lar, devido a problemas de comportamento adquiridos no abrigo (Stafford, 2007). Vale ainda ressaltar que estabelecer critérios de recolhimento dos animais pelo estabelecimento, tais como potenciais transmissores de zoonoses e cães mordedores, animais em sofrimento em via pública $\mathrm{e}$ provenientes de denúncias de maus-tratos, bem como aumentar os programas de adoção e castração seletiva nos municípios, pode contribuir para que um número menor de animais adentre os abrigos e um número maior desses animais seja realocado em novos lares. Entendese como castração seletiva uma das estratégias que compõem um programa de manejo humanitário de cães e gatos semidomiciliados e não domiciliados, cujo objetivo é reduzir o abandono de animais advindos de crias indesejadas (Componentes..., 2014).

Os resultados relativos às características dos recintos demonstram que existiam cães e gatos em instalações inadequadas, que os privavam severamente de expressar seu comportamento social natural, comprometendo sua liberdade 
ambiental, comportamental e psicológica, caracterizando, assim, baixo grau de bem-estar. Portanto, há necessidade de modificações nas instalações físicas e no manejo dos animais, como manutenção dos cães em duplas, introdução de solário para os cães e para os gatos, e passeios diários com os cães em guia. $\mathrm{O}$ passeio com guia pode ser auxiliado por um programa envolvendo voluntariado de munícipes interessados, como ocorre nos CCZ de São Paulo (Seja..., 2017). Apenas quatro abrigos incluíram algum tipo de enriquecimento ambiental para cães e gatos expressarem comportamento lúdico, tais como bolinhas, e um abrigo incluiu o recurso arranhador para gatos expressarem seu comportamento natural de arranhar com as garras. As respostas sugeriram que os cavalos são animais mais negligenciados em relação as suas necessidades de ter um local para descanso. Broom e Fraser (2010) apontaram a importância da socialização diária de 25 minutos para cães; verticalização, toca e arranhador para gatos; e cama e casqueamento para cavalos.

Apesar do esforço aparente dos municípios para manter os animais livres de fome e sede prolongadas e subnutrição, oferecendo alimento uma ou mais vezes ao dia, a boa nutrição pode ser garantida em um abrigo apenas quando todos os animais têm acesso à quantidade necessária de alimento diariamente. As recomendações diárias são para que a quantidade em gramas de determinada ração esteja de acordo com o peso do animal, com a existência de um comedouro por animal e com a verificação do "escore corporal adequado" do animal (Barnard et al., 2014). Sem esses cuidados na gestão, os animais podem estar sem acesso ao alimento adequado e em sofrimento.

A limpeza e desinfecção das instalações dependem não apenas das etapas do manejo e dos produtos utilizados (Brasil, 2017), mas também dos materiais das instalações (Miller e Zawistowski, 2014). Menos da metade dos abrigos apresentava piso de cimento queimado, embora se saiba que outros materiais podem comprometer a sua limpeza e desinfecção. Tal situação é crítica, pois, em abrigos de animais, o controle de doença infecciosa é um dos maiores desafios (Pesavento e Murphy, 2013; Miller e Hurley, 2011). Além disso, treinar os funcionários para que utilizem os produtos de limpeza em concentração e ordem correta garante a limpeza adequada e evita o desperdício de produtos de limpeza, ou seja, de recurso público (Miller e Zawistowski, 2014).

As áreas de quarentena, isolamento e de animais sadios são áreas básicas e fundamentais para abrigos. No presente estudo, foi possível verificar que menos da metade dos abrigos tinham instalações específicas para separar animais doentes dos sadios, porém havia um esforço em improvisar locais de isolamento nos abrigos que não as tinham. No entanto, surpreendentemente, esse esforço não foi uma realidade em um dos abrigos onde o respondente citou a falta de interesse do gestor e do profissional responsável pelos animais do abrigo em valorizar a vida e o bem-estar dos cães. O controle de doenças infecciosas e parasitárias em abrigos é um desafio (Pesavento e Murphy, 2013), e o não atendimento dessa liberdade sanitária compromete severamente o bem-estar dos animais. Observou-se, neste estudo, o agravante de que, em $88 \%$ dos estabelecimentos, os responsáveis não se sentiam confiantes em diagnosticar e realizar a eutanásia em animais em que tal procedimento fosse recomentado pela ICAM (Componentes..., 2014), havendo, portanto, grande possibilidade de serem mantidos animais em sofrimento. Assim, animais não adotados permanecem nos abrigos até o fim da vida. Como métodos alternativos para que os animais doentes sejam tratados e os saudáveis não fiquem expostos ao risco, alguns municípios podem estabelecer parcerias ou convênios com universidades de veterinária, com clínicas particulares, ONGs, ou ainda incentivar o voluntariado de lares temporários. Outros municípios sugerem adotar os programas de cão comunitário (Pereira et al., 2017).

Nos 17 municípios, a maioria dos respondentes citou que gostaria de melhorias na estrutura física dos abrigos, o que é importante para que os animais fiquem mais bem alojados. Entretanto, há melhorias que podem ocorrer independentemente dos recursos públicos disponíveis, como, capacitar a equipe quanto ao manejo humanitário dos animais, à etologia e ao bem-estar animal; atentar-se às necessidades básicas de uma boa alimentação e suprimento de água, de um local para descanso; proporcionar socialização dos animais com outros animais e pessoas; promover passeios externos diariamente, podendo ser em guia; divulgar 
guarda responsável e adoção de animais. Todas essas atividades não requerem recursos importantes, como é o caso de reforma de instalações. Anjos et al. (2016) também verificaram a necessidade de instalações apropriadas que respeitem as normas de bemestar animal, além da promoção de ações educativas que independem das instalações adequadas nas 75 estruturas físicas que alojam animais em UVZs/CCZs, canis e/ou similares referentes a 10 estados brasileiros participantes de sua pesquisa com 97 estabelecimentos.

Dos 17 municípios participantes, 10 afirmaram ter respaldo legal municipal para proteção animal. Em Curitiba, por exemplo, dentre as leis municipais, existe a Lei $\mathrm{n}^{\circ} 14.741 / 2015$, que proíbe a tração animal; a Lei no ${ }^{\circ} 13.908 / 2011$, que estabelece sanções e penalidades administrativas para aqueles que praticarem maus-tratos aos animais; e a Lei $\mathrm{n}^{\circ} 13.558 / 2010$, que dispõe sobre o comércio e doação de animais. É importante o acompanhamento dos resultados para os animais após a aprovação de novas leis de proteção animal. Por exemplo, muitos cavalos passaram a trabalhar nas regiões metropolitanas, bem como canis clandestinos de criação se realocaram para essas regiões onde a lei municipal não existe e a lei federal não está sendo fiscalizada. No Brasil, existe a Lei Federal de Crimes Ambientais $n^{\circ}$ 9605/98, art.32, a qual protege os animais contra maus-tratos em todo o território nacional, e deve, dessa forma, ser usada nos municípios que não possuem leis municipais. Diante de denúncias de maus-tratos em CCZs, em 2015, ocorreu a primeira Comissão Parlamentar de Inquérito (CPI) para investigação do Poder Legislativo federal nesses estabelecimentos (Brasil, 2015). Isso reforça a necessidade de formulação e envio de projetos de leis às Câmaras Municipais, os quais ajudem a coibir e punir maus-tratos aos animais e que garantam programas de controle populacional de cães e gatos de forma tecnicamente correta e eticamente aceitável.

É fundamental entender que abrigos de animais são locais que atendem animais em risco, mas não combatem a causa de eles existirem, que é o abandono desses animais. Portanto, para melhorar a qualidade de vida de cães, gatos e cavalos abrigados, é necessário visar trabalhar com o número de animais mais próximo de zero. Isso pode ser possível diminuindo a demanda por recolhimento, por meio de programas contínuos de educação da população em guarda responsável, controle do comércio animal, registro e identificação, coibição do abandono e de outras formas de maus-tratos, castração seletiva de cães e gatos e incentivo à adoção. Muitas melhorias para o bem-estar dos animais de abrigos advêm de fatores que independem do recurso financeiro público para reestruturação física dos abrigos, ainda que esta seja importante e deva ser providenciada. Há necessidade de incluir uma cama por animal em todos os recintos e para todas as espécies, atender de forma efetiva às necessidades nutricionais, promover a interação social dos animais e com o ambiente externo de forma regular e segura, bem como respeitar a quantidade e o peso dos animais por tamanho dos recintos. Recintos que isolam o animal da interação social e que comprometem o seu conforto foram frequentes e devem ser abolidos. Isso é possível quando aplicados os princípios e os conhecimentos em medicina veterinária de abrigos e medicina veterinária do coletivo, para a otimização da gestão desses estabelecimentos e para o manejo dos animais alojados.

\section{CONCLUSÕES}

A gestão e as instalações de abrigos vinculados ao poder público no Paraná passam por um momento de transformação de conhecimento e de reestruturação, respectivamente. Em sua maioria, são de responsabilidade das Secretarias de Saúde. Todos os municípios abrigavam cães e mantinham animais para adoção, e quase a metade dos estabelecimentos abrigava gatos e cavalos. Os animais de um mesmo abrigo são mantidos em diferentes condições de instalações e manejo, e, dessa forma, o grau de bem-estar de alguns animais pode estar muito mais comprometido que o de outros. Recintos que isolam o animal da interação social e que comprometem o seu conforto foram frequentes e devem ser abolidos. 


\section{REFERÊNCIAS}

ANIMAIS em situação de risco terão centro de referência. Curitiba: Agência de Notícias da Prefeitura de Curitiba, 2016. Disponível em: <http://www.curitiba.pr.gov.br/noticias/animaisem-situacao-de-risco-terao-centro-dereferencia/40674>. Acessado em: 3 jun. 2017.

ANJOS, C.B.; PEREIRA, L.R.M. et al. Diagnóstico situacional dos serviços de controle de zoonoses. Rev. Clín. Vet., v.22, p.8-12, 2016.

BARNARD, S.; PEDERNERA, A.; VELARDE, P.; DALLA, V.P. shelter quality - welfare assessment protocol for shelter dogs. Salignan: IRSEA, 2014. 47p.

BRASIL. Câmara dos Deputados. Criação de Comissão Parlamentar de Inquérito, com a finalidade de investigar os fatos determinados como maus-tratos de animais. n.13. 17 jul. 2015. Diário Oficial da União. Brasília, 2015.

BRASIL. Ministério da Agricultura, Pecuária e Abastecimento. CSPet- Câmara Setorial da Cadeia Produtiva de animais de estimação. Manual de boas práticas na criação de animais de companhia. 2017. 17p. Disponível em: $<$ http://www.agricultura.gov.br/assuntos/camaras -setoriais-aticas/documentos/camarassetoriais/animais-e-

estimacao/manual_7ro_pet.pdf/view>._Acessado em: 02 jun. 2017.

BRASIL. Ministério da Saúde. Secretaria de Vigilância em Saúde. Departamento de Vigilância das Doenças Transmissíveis. Coordenação - Geral de Doenças Transmissíveis. Atividades das unidades de vigilância de zoonoses. In: Manual de vigilância, prevenção $e$ controle de zoonoses: normas técnicas $\mathrm{e}$ operacionais. cap.2. Brasília, 2016. p.24-36.

BROOM, D.M. Indicators of poor welfare. $B r$. Vet. J., v.142, p.524-526, 1986.

BROOM, D.M.; FRASER, A.F. Comportamento e bem-estar de animais domésticos. 4.ed. São Paulo: Manole. 2010. 438p.

COMPONENTES de um programa abrangente de controle da população canina. In: Guia de controle humanitário da população canina. [s.1.]: ICAM, 2014. cap.C, p.12-16.
CURITIBA. Câmara Municipal de Curitiba. Lei 13.914/2011 que disciplina o comércio de animais de estimação no Município de Curitiba. Diário Oficial Municipal. Curitiba, PR, n.98, 27 dez. 2011. p.1-7.

CURITIBA. Câmara Municipal de Curitiba. Lei 14.741 que dispõe sobre a proibição de uso de veículos da tração animal e exploração animal para tal fim no município de Curitiba. Diário Oficial Municipal. Curitiba, PR, 27 out. 2015. p.1-2.

CURITIBA. Câmara Municipal de Curitiba. Lei $\mathrm{n}^{\circ} 13.908 / 2011$ que estabelece no âmbito municipal de Curitiba, sanções e penalidades administrativas para aqueles que praticarem maus-tratos aos animais e dá outras providências. Diário Oficial Municipal. Curitiba, PR, dez. 2011.

CURSO de controle animal. Orlando: ITEC, $2017 . \quad$ Disponível em: <http://itecbr.org/site/curso_lista.php>. Acessado em: 31 jul. 2017.

DECLARAÇÃO de Cambridge, UK. São Leopoldo: IHU, 2012. Disponível em: <http://fcmconference.org/>. Acessado em: 22 mai. 2017.

DHAMA, K.; CHAKRABORTY, S.; KAPOOR, S. et al. One world, one health - veterinary perspectives. Adv. Anim. Vet. Sci.. v.1, p.5-13, 2017.

GOURKOW, N.; FRASER, D. The effect of housing and handling practices on the welfare, behaviour and selection of domestic cats (Felis sylvestris catus) by adopters in an animal shelter. Anim. Stud. Repository, . v.15, p.371-377, 2006.

POPULAÇÃO NO ESTADO. IBGE - Instituto Brasileiro de Geografia e Estatística, 2018. Disponível em: <https://cidades.ibge.gov.br/ brasil/pr/curitiba/panorama >._Acessado em: 16 set. 2018 .

LUNS, R.C.L.A.; LUNS, E.D. Estrutura de canis municipais e ações de manejo populacional de cães e gatos em municípios do estado de Minas Gerais, Brasil. Rev. Educ. Cont. Med. Vet. Zootec. CRMV-SP, v.15, p.64-65, 2017. (Resumo). 
MILLER, L.; ZAWISTOWSKI, S. Introduction to animal sheltering. In: Shelter medicine for veterinarians and staff. 2.ed. Iowa: WileyBlackwell, 2013. cap.1, p.3-12.

MILLER, L.; ZAWISTOWSKI, S. Shelter medicine for veterinarians and staff. 2ed. Iowa: Wiley-Blackwell, 2014. 42p.

MILLER, L; HURLEY, K. Sanitation and disinfection. In:. Infectious disease management in animal shelters. Iowa: WileyBlackwell, 2011. cap.4, p.49-60.

MINERO, M.; COSTA, E.D.; DAI, F. et al. Animal welfare indicators. Welfare assessment protocol for horses. 2015. Pirassununga, SP: USP. 79p.

MINISTÉRIO da Saúde. Em dois anos, Ministério da Saúde amplia em 95\% investimentos em ações e serviços. Acessado em: $<$ http://portalms.saude.gov.br/noticias/agenciasaude/em-dois-anos-ministerio-da-saude-ampliaem-95-investimentos-em-acoes-e-servicos> Acessado em: 9 fev. 2018.

MOLENTO, C.F.M. Public health and animal welfare. In: APPLEY, M.; WEARY, D.M.; SANDOE, P. Dilemmas in animal welfare. London: WSPA, 2014. p.102-123.

PARANÁ, Secretaria Municipal de Governo torna público a Lei Estadual n.17.422/2012 que dispõe sobre o controle ético de cães e gatos no Estado do Paraná que disciplina o comércio de animais de estimação no município de Curitiba. Diário Oficial Estadual do Paraná, 19 dez. 2012. n.8862.
PEREIRA， E.F.L.; CONSTANTINO, C.; MARCONCIN, S.; BIONDO, A.W. Proposta de implantação do Programa Cão Comunitário para o município de Pinhais, Estado do Paraná, Brasil. In: CONFERÊNCIA INTERNACIONAL DE MEDICINA VETERINÁRIA DO COLETIVO, 7., 2016, São Paulo. Anais... São Paulo: CRMVSP, 2016. n.1, p.87-88. (Resumo).

PESAVENTO, P.A.; MURPHY, B.G. Common and emerging infectious diseases in the animal shelter. Vet. Pathol., v.51, p.478-491, 2013.

PINILLOS, R.; APPLEBY, M.C.; MANTECA, $\mathrm{X}$. et al. One welfare - a platform for improving human and animal welfare. Vet.y Rec., v.179, p.412-413, 2016.

RX DOS CCZs e canis - ação do CRMV-RS fiscalizou 41 estabelecimentos no Rio Grande do Sul. Vet. Zootec., v.19, p.6-7, 2014.

SÃO PAULO. Recolhimento de animais. Programa de controle de populações de cães e gatos do estado de São Paulo. Secretaria de Estado da Saúde de São Paulo. 2006. v.3, cap.6, p.81-104.

SEJA um voluntário CCZ. São Paulo: Prefeitura se São Paulo, 2017. Disponível em: <http://www.capital.sp.gov.br/cidadao/animais/a nimais-domesticos/seja-um-voluntario-ccz>. Acessado em: 4 jun. 2017.

STAFFORD, K. Dogs in shelter. In: The welfare of dogs. Dordrecht: Springer, 2007. v.4, cap.10, p.179-198.

VOCÊ sabe o que é bem-estar animal? Belo Horizonte: CFMV, 2017. Disponível em: <http://portal.cfmv.gov.br/uploads/files/11_04_2 017_Folder40x21cm.pdf>. Acessado em: 4 jun. 2017. 